\title{
Direct Determination of Trace Lead in Seawater by Inductively Coupled Plasma Mass Spectrometry After Photochemical Vapor Generation
}

\author{
Shuzhen $\mathrm{Li}^{\mathrm{a}, \mathrm{c}}$, Ying Gao ${ }^{\mathrm{a}, \mathrm{b}, *}$, Ying $\mathrm{Yu}^{\mathrm{b}}$, Hongyan $\mathrm{He}^{\mathrm{b}}$, Xiaorong $\mathrm{Hu}^{\mathrm{c}}$, Shijun $\mathrm{Ni}^{\mathrm{b}}$, \\ Zeming Shi ${ }^{\mathrm{b}}$, Xiuhong Peng ${ }^{\mathrm{b}}$, and Rui Liu \\ ${ }^{a}$ State Key Laboratory of Geohazard Prevention and Geoenvironment Protection, \\ Chengdu University of Technology, Chengdu, Sichuan 610059, P.R. China \\ ${ }^{b}$ College of Earth Sciences, Chengdu University of Technology, Chengdu, Sichuan 610059, P.R. China \\ c College of Materials and Chemistry \& Chemical Engineering, \\ Chengdu University of Technology, Chengdu 610059, P.R. China
}

\section{INTRODUCTION}

The presence of heavy metals poses a potential threat to marine ecosystems due to their toxicity, resistance to degradation, and consequent tendency to bioaccumulation $(1,2)$. Among them, lead $(\mathrm{Pb})$ is toxic to humans, aquatic plants, and animals at trace levels (3-5) and is widely regarded as a good indicator of heavy metal pollution in marine environments caused by anthropogenic activities $(6,7)$. Elucidation of the distribution and concentration of lead in seawater is of great importance for identification of the contamination source and contamination prevention $(1,8,9)$.

Atomic spectrometry-based techniques are the most popular methods for the determination of trace metals in environmental samples. Inductively coupled plasma mass spectrometry (ICP-MS) is one of the most powerful techniques due to its low detection limits, wide linear range, and high sample throughput $(10,11)$. However, direct determination of lead in seawater samples remains a challenge due to their extremely low concentrations and high salt matrix (1214). Therefore, preconcentration and purification before detection is required for the analysis of lead in seawater. Solvent extraction and extraction onto chelating resin columns followed by atomic spectrometry detection were developed

*Corresponding autbor.

E-mail: ying.gaoy@gmail.com Tel.: 86-28-8407-8773

\section{ABSTRACT}

A novel method is developed for the determination of lead in seawater samples using nickelassisted photochemical vapor generation (PVG) coupled with inductively coupled plasma mass spectrometry (ICP-MS). The severe matrix effect of seawater on the suppression of the lead signal was efficiently eliminated by using a mixture of $15 \mu \mathrm{g} \mathrm{g}^{-1}$ $\mathrm{Ni}^{2+}$ and $10 \%(\mathrm{v} / \mathrm{v})$ formic acid as a photochemical reduction medium, making direct determination of lead in seawater samples feasible. A method detection limit of $0.003 \mathrm{ng} \mathrm{g}^{-1}$ based on external calibration was obtained, and the sampling frequency of $20 \mathrm{~h}^{-1}$ was achieved with a 30-second sample loading time and a $1.25-\mathrm{mL}$ sample consumption. The relative standard deviation of the measurement results was $3.7 \%(\mathrm{RSD}, \mathrm{n}=7$ ) in seawater spiked with $1 \mathrm{ng} \mathrm{g}^{-1}$ $\mathrm{Pb}^{2+}$ solution. The proposed method was successfully applied for the analysis of one standard reference material (SeawaterQC3163) and three seawater samples (collected from Shanghai, Haikou, and Sanya, P.R. China) with satisfactory results.

(15-17). But these methods are usually relatively labor-intensive (i.e., reagent purification and sample processing) and time-consuming as they often require large sample volumes (hundreds of milliliter to liter scale). A $\mathrm{Mg}(\mathrm{OH})_{2}$ co-precipatation method with low procedural blank was also proposed for the determination of lead in seawater (18). Nevertheless, it could result in high content of sea salt in a sample matrix which can clog the nebulizer and leave deposits on the ICPMS cones.

Chemical vapor generation (CVG) is a widely used sample introduction method for trace metal detection in atomic spectrometry which can greatly increase sample introduction efficiency and efficiently separate the analyte from its troublesome sample matrix (19). Conventional CVG methods often involve using high blank oxidation reagents and unstable reduction reagents, making it difficult to determine trace/ultratrace concentrations of $\mathrm{Pb}$ in environmental samples. Purification of reagents before use or high purity reagents is always required (20, 21). Photochemical vapor generation (PVG), utilizing free radicals generated by photoredox reactions in the presence of low molecular weight organic compounds, not only remains the major advantage of CVG but also provides simpler reactions (22-24). For lead determination, metal ion-assisted PVG was developed for the analysis of sediments, soils, and river waters (25). In the presence of $\mathrm{Ni}^{2+}$, a significant improvement in PVG efficiency of lead was achieved. The proposed method is simple, with low blanks compared to conventional CVG for lead, and avoids unstable reagents. However, the severe matrix effect is still a problem for the direct determination of 
lead in seawaters. The signal from $\mathrm{Ni}^{2+}$ was significantly suppressed in the presence of high concentrations of chloride, resulting in low PVG efficiency of $\mathrm{Ni}$ as well as a greatly decreased PVG efficiency of lead. Recently, Duan et al. (26) proposed a new method for the determination of trace lead by generating volatile lead species in the presence of $0.90 \%(\mathrm{v} / \mathrm{v})$ acetic acid and $0.03 \%(\mathrm{v} / \mathrm{v})$ hydrochloride acid under UV irradiatinon. This technique is simple, convenient, and has low blank. But the suppression effect of high concentration inorganic anions is also a problem for the direct analysis of seawater samples.

The purpose of this work was to develop a sensitive, simple, and direct method for the accurate determination of trace lead in seawater samples by nickel ion-assisted PVG coupled with ICP-MS detection. The accuracy of the proposed method is demonstrated by successful analysis of three seawaters.

\section{EXPERIMENTAL}

\section{Instrumentation}

An ELAN@ DRC ${ }^{\text {TM }}$-e ICP-MS (PerkinElmer, Inc., Shelton, CT, USA), equipped with quartz torch and alumina sample injector tube, was used. The fitted GemTip ${ }^{\mathrm{TM}}$ cross-flow nebulizer and a corrosion-resistant double-pass Ryton ${ }^{\circledR}$ spray chamber mounted outside the torch box were replaced by a PVG-system for lead determination. A model FIA-3110 flow injection pump system (Vital Instruments Co. Ltd., Beijing, P.R. China) was used for the introduction of sample solutions to the PVG system. A schematic of the UV-PVG photoreactor interfaced to the ICP-MS is similar to a previous report (25). The UV-PVG system consists of a $19 \mathrm{~W}$ thin film flow-through lamp (Beijing Titan Instruments Co., Beijing, P.R. China) loosely covered with aluminum foil to shield the operator from exposure to the UV. Argon carrier gas was introduced through a " $T$ " connection between the outlet of the photoreactor and a tandem set of two homemade gasliquid separators (GLSs, 2 mL internal volume) maintained at $0{ }^{\circ} \mathrm{C}$ by immersion in an ice bath to minimize any transport of liquid droplets derived from condensation of water vapor to the ICP. The generated analyte vapors were directed from the outlet of the last GLS to the ICP-MS via a 0.25 -m length of Teflon ${ }^{\circledR}$ lined Tygon ${ }^{\circledR}$ tubing. Optimization of the ICP-MS parameters was performed as recommended by the manufacturer. Optimum conditions for PVG were investigated independently. Typical operating conditions are summarized in Table 1.

\section{Reagents and Standard Solutions}

All reagents were of analytical reagent grade or better, and deionized water (DIW) was used throughout. ACS grade formic acid was obtained from Aladdin Industrial Corporation (Shanghai, P.R. China). Stock solutions of lead and nickel with the concentration of 1000

\section{TABLE I}

ICP-MS Instrumental Operating Parameters

\begin{tabular}{lr}
\hline Instrument Settings & ICP-MS \\
\hline RF power & $1175 \mathrm{~W}$ \\
plasma gas flow & $15 \mathrm{~L} \mathrm{~min}^{-1}$ \\
Auxiliary gas flow & $1.2 \mathrm{~L} \mathrm{~min}^{-1}$ \\
Nebulizer gas flow & $1.0 \mathrm{~L} \mathrm{~min}^{-1}$ \\
Scanning mode & Peak hopping \\
Isotope monitored & $208 \mathrm{~Pb}$ \\
Resolution & $0.7 \mathrm{amu}$ \\
$\begin{array}{l}\text { Dwell time } \\
\text { Dead time }\end{array}$ & $30 \mathrm{~ms}$ \\
\hline & $50 \mathrm{~ns}$ \\
\hline Sample flow rate & $\mathrm{UV}-\mathrm{PVG}$ \\
$\begin{array}{l}\text { Ar carrier gas flow } \\
\text { rate to PVG }\end{array}$ & $1.0 \mathrm{~min} \mathrm{~min}^{-1}$ \\
\hline
\end{tabular}

$\mu g \mathrm{~g}^{-1}$ were purchased from Environmental Express (South Carolina, U.S.). Lead working standard solution was prepared by dilution of the stock solution with $0.1 \%$ $\mathrm{HCOOH}$. High-purity $\mathrm{NaCl}$ (trace SELECT, >99.999\%) was obtained from Aladdin Industrial Corporation (Shanghai, P.R. China). A 2 M BrCl solution was prepared in a fume hood by dissolution of $27 \mathrm{~g}$ of reagent grade $\mathrm{KBr}$ (Fisher Scientific, Ottawa, Canada) in $2.5 \mathrm{~L}$ of $\mathrm{HCl}$ in a glass container, followed by slow addition of $38 \mathrm{~g}$ reagent grade $\mathrm{KBrO}_{3}$ (Fisher Scientific, Ottawa, Canada). A rinse solution containing $0.04 \mathrm{M} \mathrm{BrCl}$ was prepared by dilution of the $2 \mathrm{M} \mathrm{BrCl}$ with deionized water (DIW) to efficiently eliminate any carry-over between the samples. A certified reference material QC3163 Seawater was obtained from Sigma Aldrich for method validation.

Three seawater samples were analyzed for method validation, which were collected from Sanya (Hainan, P.R. China), Haikou (Hainan, P.R. China), and Shanghai (Chongmingdao, P.R. China), respectively.

\section{Standard Additions Sample Preparation and Analysis Procedure}

For the determination of lead in seawater samples, standard addition calibration was applied. Three replicate subsamples of $10 \mathrm{~g}$ of each seawater sample were weighed into precleaned polyethylene bottles. A 10-g mass of a solution containing $20 \%$ formic acid (FA) and $0.3 \mathrm{~g}$ of a 1000-g g- ${ }^{1} \mathrm{Ni}$ stock solution were added to each sample, resulting in a final concentration of $10 \% \mathrm{FA}$ and $15 \mu \mathrm{g} \mathrm{g}^{-1} \mathrm{Ni}^{2+}$. Appropriate amounts of the standard solution of $\mathrm{Pb}^{2+}$ were added to each spiked seawater sample to obtain approximately a 1-, 2-, and 4-fold increase in the $\mathrm{Pb}$ concentration, respectively. The unspiked and spiked samples were then diluted to $20 \mathrm{~g}$ with DIW. 
Three sample blanks were prepared containing $10 \% \mathrm{FA}, 15 \mu \mathrm{g} \mathrm{g} \mathrm{g}^{-1} \mathrm{Ni}$, and $1.75 \% \mathrm{NaCl}$ to match the matrix of the seawater samples. The sample solutions were subjected to UV-PVG-ICP-MS detection as described earlier. Briefly, the sample solution was quickly delivered to the PVG reactor at a sample flow rate of $2.5 \mathrm{~mL} \mathrm{~min}^{-1}$ and remained in the reactor for $50 \mathrm{sec}$ onds by stopping the pump for photochemical reduction of $\mathrm{Pb}$ into volatile species. Then the irradiated sample solution was transferred to the GLSs from the PVG reactor for analysis by ICP-MS at the same sample flow rate. For the next analysis, a solution of $0.04 \mathrm{M} \mathrm{BrCl}$ was used to efficiently rinse the system for 50 seconds to eliminate any carryover between the samples. The peak area of the ${ }^{208} \mathrm{~Pb}$ isotope was used to construct a standard additions calibration curve for each sample.

\section{RESULTS AND DISCUSSION}

Serious suppression effects often occur when detecting metal ions in seawater samples by the PVG-based technique (27-29). According to the previous report, volatile species of $\mathrm{Pb}$ can be efficiently generated in $5 \%$ formic acid and $3 \mu \mathrm{g} \mathrm{g}^{-1} \mathrm{Ni}^{2+}$ under UV irradiation (25). During initial experiments, a 5-ng g-1 $\mathrm{Pb}$ standard solution containing 5\% formic acid, $3 \mu \mathrm{g} \mathrm{g}^{-1} \mathrm{Ni}$, and $1.75 \%$ $\mathrm{NaCl}(\mathrm{w} / \mathrm{v})$ (matching matrix in the prepared seawater solutions) was introduced to the PVG reactor. The response from the solution was only $10 \%$ of that obtained from a matrix-free standard solution, showing the severe suppression effect of the sample matrix on lead detection in seawater samples. It was found that the PVG efficiency of $\mathrm{Ni}^{2+}$ was also significantly suppressed in the presence of high concentrations of chloride. It may be that the oxidative radicals generated from the sample matrix largely consumed the reductive radicals arising from photodecomposition of formic acid, resulting in the low PVG efficiencies of $\mathrm{Ni}$ and $\mathrm{Pb}$. Increasing the concentration of formic acid could provide more available reductive radicals for the photochemical reduction of the analytes in seawater samples and potentially alleviate the effect of the seawater matrix. Due to the suppression effect of the sample matrix, spiked seawater instead of standard solution was used to investigate optimum PVG conditions for the determination of $\mathrm{Pb}$.

\section{Optimization of UV-PVG system}

The formic acid concentration, $\mathrm{Ni}^{2+}$ concentration, UV irradiation time, and argon carrier gas flow rate comprised the four basic parameters which determined the PVG efficiency of the analyte and the transport efficiency to the ICP-MS. These parameters were investigated to obtain optimized responses on lead detection.

PVG efficiencies highly depend on the type and concentration of organic reductants used $(28,30-32)$. The effect of formic acid concentration in the range of $1 \%-40 \%(\mathrm{v} / \mathrm{v})$ on the response (peak area normalized to the maximum achieved) of $\mathrm{Pb}$ in seawater spiked with $5 \mathrm{ng} \mathrm{g}^{-1}$ $\mathrm{Pb}$ solution is shown in Figure 1.
The signal response of ${ }^{208} \mathrm{~Pb}$ increased with an increasing concentration of formic acid from 1\% to $10 \%(\mathrm{v} / \mathrm{v})$, and then decreased beyond $10 \%$. Obviously, the optimum concentration of formic acid was higher than that of a previous report $(5 \%, \mathrm{v} / \mathrm{v})$. It suggests that reductive radicals arising from photodecomposition of formic acid were largely consumed by potentially oxidative radicals generated from the sample matrix, decreasing the available reductive radicals for the reduction of lead. Therefore, a higher concentration of formic acid was required for the efficient reduction of lead in seawater compared to that in a standard solution. But a further increase in concentration of formic acid above $10 \%$ (v/v) may lose penetration depth of the UV radiation into the sample as the absorption of the solution increases. In addition it may also increase possible side reactions or photodecomposition of the product and its redissolution in the aqueous phase. Consequently, 10\% (v/v) formic acid was selected for subsequent measurement.

Metal ions play important roles for the reduction of $\mathrm{Pb}$ in a PVG system. The presence of $\mathrm{Ni}^{2+}$ in formic acid solution can significantly improve the PVG efficiency of $\mathrm{Pb}$ (25). Recently, ferric ion-

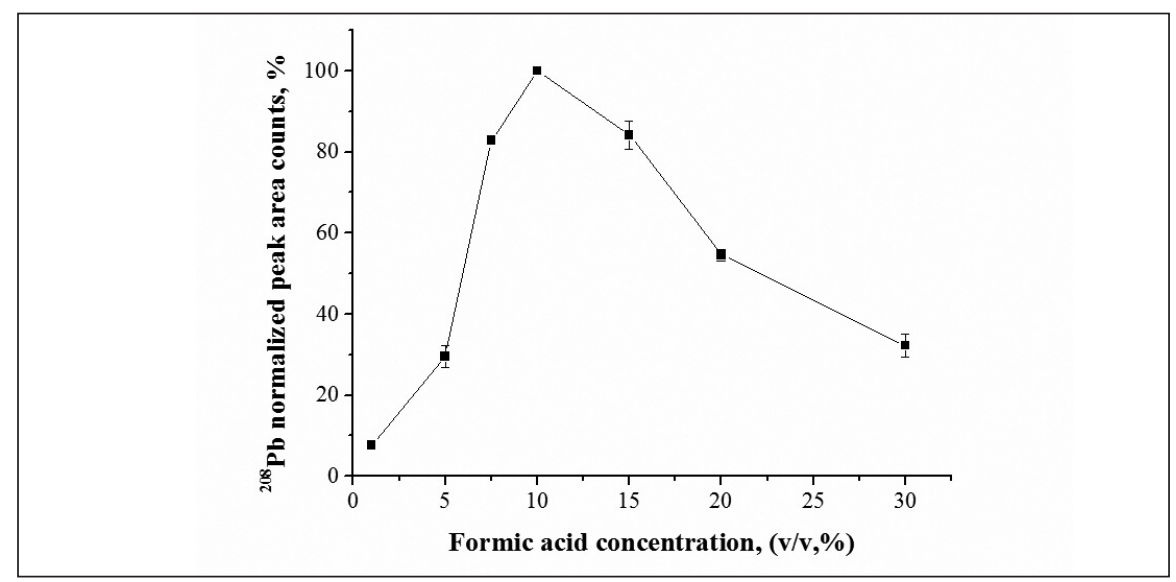

Fig. 1. The effect of formic acid concentration on lead detection. 
induced enhancement of PVG was also observed for As detection (33). The effect of added $\mathrm{Ni}^{2+}$ concentration in the range of $0-30 \mu \mathrm{g} \mathrm{g}^{-1}$ on the response (peak area normalized to the maximum achieved) of $\mathrm{Pb}$ in seawater spiked with $5 \mathrm{ng} \mathrm{g}^{-1} \mathrm{~Pb}$ solution is shown in Figure 2. The peak area of ${ }^{208} \mathrm{~Pb}$ increased with an increase in $\mathrm{Ni}^{2+}$ concentration from $0 \mu \mathrm{g} \mathrm{g}^{-1}$ to $15 \mu \mathrm{g} \mathrm{g}^{-1}$, followed by a slight decrease at higher concentrations. The optimal concentration of $\mathrm{Ni}^{2+}$ for the efficient generation of volatile $\mathrm{Pb}$ in seawater was five times higher than that obtained from standard solution, which was likely owing to the severe suppression of the generation of volatile $\mathrm{Ni}^{2+}$ in the presence of high concentrations of $\mathrm{Cl}^{-}$. Although the mechanism of metalion-assisted PVG reaction was not clear, the generation of significant amounts of volatile $\mathrm{Ni}$ species were needed to enhance charge transfer reactions of $\mathrm{Pb}$ and to facilitate the reduction of $\mathrm{Pb}$. Therefore, $15 \mu \mathrm{g} \mathrm{g}^{-1} \mathrm{Ni}^{2+}$ was selected for all subsequent measurements.

The dosage of UV radiation received by sample solution mainly determines the efficiencies of radical formation and the vapor generation of lead. The effect of UV irradiation time over the range of 30-150 seconds was investigated using seawater spiked with $5 \mathrm{ng} \mathrm{g}^{-1}$ $\mathrm{Pb}$ containing $10 \%$ formic acids and $15 \mu \mathrm{g} \mathrm{g}^{-1} \mathrm{Ni}^{2+}$. As shown in Figure 3, the responses initially sharply increased as irradiation time increased from 30 to 50 seconds. Thereafter, a quick decrease occurred with a further increase in irradiation time. The relatively short irradiation time leads to inefficient generation of volatile $\mathrm{Pb}$ species, and with increased irradiation time leads to the reoxidation of volatile $\mathrm{Pb}$ species by photo-decomposed oxidative radicals from the sample matrix. The optimal UV irradiation time of $\mathrm{Pb}$ in seawater samples was much less than reported previously (25). This probably is due to the combined effect of sample matrix and the air temperature around the UV lamp. After UV irradiation with 50 seconds at room temperature $\left(25^{\circ} \mathrm{C}\right)$, the temperature of the sample solution through the UV reactor was nearly $60^{\circ} \mathrm{C}$. When a mini-fan was set under the UV reactor to accelerate circulation of air around the UV lamp, the optimal UV irradiation time was delayed to 100 seconds. Furthermore, the temperature of the sample solution after 50 seconds irradiation was down to $48^{\circ} \mathrm{C}$, which suggested that the air temperature around the UV lamp influenced the kinetics of PVG for $\mathrm{Pb}$. Therefore, an irradia- tion time of 50 seconds (at $25^{\circ} \mathrm{C}$ ) was selected for all subsequent measurements to achieve a maximum response and reasonable sample throughput.

The argon carrier gas flow rate through GLS influences the liquid gas separation efficiency of the volatile $\mathrm{Pb}$ species as well as the depth of sampling in the plasma. The effect of argon carrier gas flow rate on the response of $\mathrm{Pb}$ from spiked seawater was optimized in the range of $0.8-1.1 \mathrm{~L} \mathrm{~min}^{-1}$. As shown in Figure 4, maximum response was obtained at the 1.0 $\mathrm{L} \mathrm{min}^{-1}$ gas flow rate. Lower carrier gas flow rates may lead to inefficient stripping and transport of the analyte from the solution to the ICP-MS; whereas higher flow rates will result in significant dilution of the analyte in the carrier gas. Therefore, the Ar carrier gas flow rate to the GLS of $1.0 \mathrm{~L} \mathrm{~min}^{-1}$ was selected for all subsequent measurements.

\section{Figures of Merit}

Under optimal experimental conditions, the signal response of lead from $1.75 \% \mathrm{NaCl}(\mathrm{w} / \mathrm{v})$ (matching the matrix in the prepared seawater solution) was approximately $90 \%$ of that from the same concentration of the matrix-free standard solution

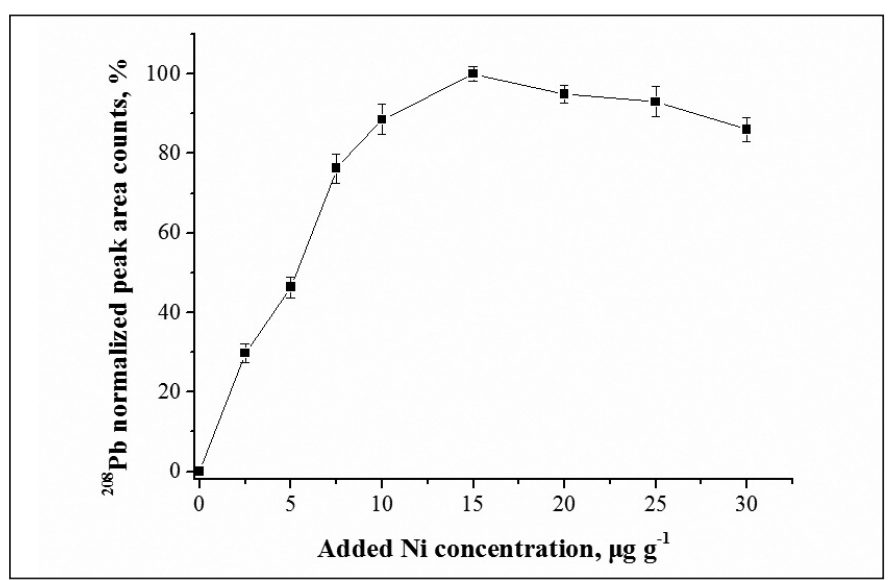

Fig. 2. The effect of $\mathrm{Ni}^{2+}$ concentration on lead detection.

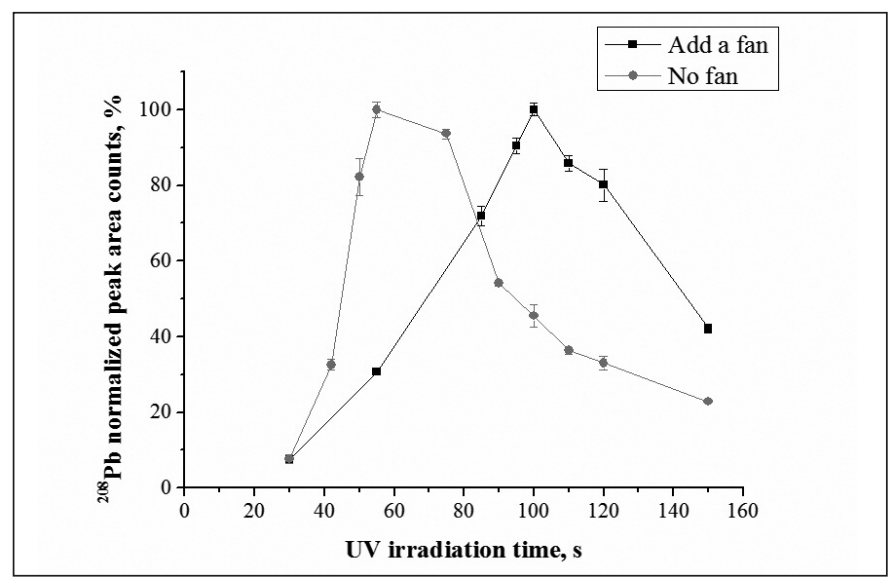

Fig. 3. The effect of $U V$ irradiation time and temperature on lead detection. 


\section{Atomic Apectroscopy \\ $\bigcup$ Vol. 38(3), May/June 2017}

with $5 \%$ formic acid and $3 \mu \mathrm{g} \mathrm{g}^{-1}$ $\mathrm{Ni}^{2+}$. A relatively good precision of $3.7 \%$ RSD was obtained from the replicate measurements of the seawater samples spiked with $1 \mathrm{ng} \mathrm{g}^{-1}$ $\mathrm{Pb}(\mathrm{n}=7)$. The sampling frequency of $20 \mathrm{~h}^{-1}$ was achieved with a 30second sample loading time and a 1.25-mL sample consumption for each analysis. Good linear response was obtained from $\mathrm{Pb}$ standard solutions prepared in the range of $0.02-200 \mathrm{ng} \mathrm{g}^{-1}$ in $1.75 \% \mathrm{NaCl}$. A method detection limit of 0.003 ng $\mathrm{g}^{-1}$ was obtained using external calibration, based on three times the standard deviation of the analyte concentration arising from the method blank which comprises a solution of $1.75 \% \mathrm{NaCl}, 10 \%$ formic acid, and $15 \mu \mathrm{g} \mathrm{g}^{-1}$ of $\mathrm{Ni}^{2+}$ in DIW (see Figure 5). Compared to photoCVG-MC-ICP-MS determination, the LOD is slightly improved, which is $0.005 \mathrm{ng} \mathrm{g}^{-1}$. It is probably due to the better measurement precision of MC-ICP-MS. But it is 30 times lower than with the direct solution nebulization method after 10-fold dilution prior to analysis (0.09 $n g \mathrm{~g}^{-1}$ ) for the analysis of seawater samples (Table II). Also, the proposed method is more sensitive than most of the traditional methods with the HG technique, and is comparable with methods by ICPMS detection after solid phase extraction. In addition, the method blank can be easily controlled as per the latest report for $\mathrm{Pb}$ detection by the PVG method (26). But this method has great advantages for the direct analysis of seawater samples.

\section{$\mathrm{Pb}$ Determination in Seawater}

To compensate for matrix effects and achieve accurate results, stan- dard additions were used for seawater analysis. Three seawater samples were analyzed under optimal experimental conditions. Seawater solutions with gravimetric additions of approximately 1-, 2-, and 4-fold the endogenous $\mathrm{Pb}$ content were prepared, yielding a calibration curve with a correlation coefficient greater than 0.999. The analytical results are listed in Table III.

TABLE II

Comparison of LODs for Pb Using Different Techniques

\begin{tabular}{lcllll}
\hline $\begin{array}{l}\text { Chemical } \\
\text { Reagents }\end{array}$ & Method & $\begin{array}{l}\text { Precon- } \\
\text { centration }\end{array}$ & Samples & LOD & Ref. \\
\hline- & ICP-MS & $\begin{array}{l}\text { PVC-packed } \\
\text { mini-column }\end{array}$ & Seawater & $7 \mathrm{pg} \mathrm{g}^{-1}$ & (14) \\
ICP-OES & $\begin{array}{l}\text { Ionic } \\
\text { imprinted } \\
\text { polymer }\end{array}$ & Seawater & $1.88 \mathrm{ng} \mathrm{g}^{-1}$ & (16) \\
& & & &
\end{tabular}

$0.28 \mathrm{~mol} \mathrm{~L}^{-1} \mathrm{H}_{2} \mathrm{O}_{2}$,

$0.1 \mathrm{~mol} \mathrm{~L}^{-1} \mathrm{HNO}_{3}$,

and $1.5 \%(\mathrm{~m} / \mathrm{v}) \mathrm{NaBH}_{4}$ HG-ICP-MS - Seawater $0.024 \mathrm{ng} \mathrm{g}^{-1}$

$1 \%(\mathrm{v} / \mathrm{v}) \mathrm{HCl}$, HG-ICP MS -

Seawater $\quad 0.008 \mathrm{ng} \mathrm{g}^{-1}$

$2 \%(\mathrm{~m} / \mathrm{v}) \mathrm{K}_{3} \mathrm{Mn}(\mathrm{CN})_{6}$,

and $2 \%(\mathrm{~m} / \mathrm{v}) \mathrm{NaBH}_{4}$

$0.90 \%$ acetic acid (v/v) PVG-ICP-MS-

Tap Water $\quad 0.0036 \mathrm{ng} \mathrm{g}^{-1}$ and $0.030 \% \mathrm{HCl}(\mathrm{v} / \mathrm{v})$ and Lake

Water

$15 \mu \mathrm{g} \mathrm{g}^{-1} \mathrm{Ni}^{2+}$ and $\quad$ PVG-ICP-MS- Seawater $0.003 \mathrm{ng} \mathrm{g}^{-1}$ This $10 \%(\mathrm{v} / \mathrm{v})$ formic acid work

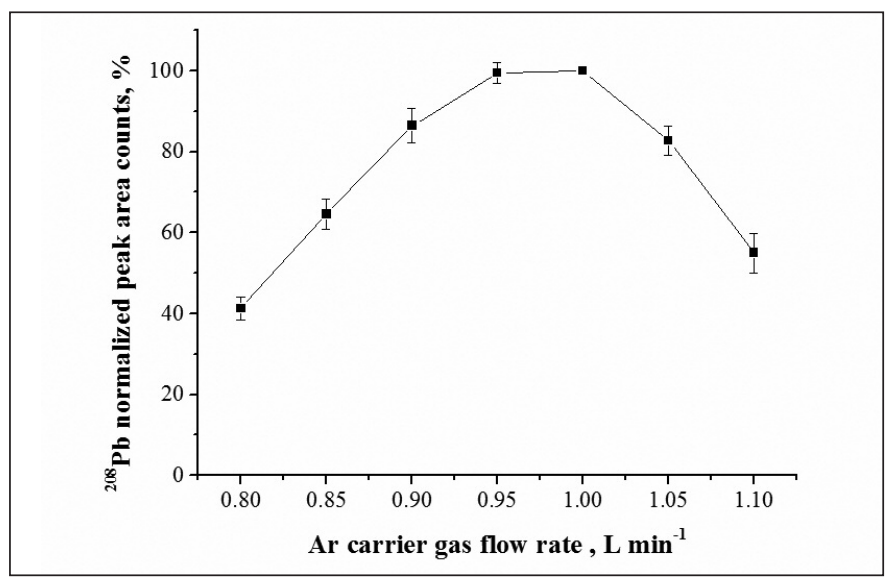

Fig. 4. The effect of Ar carrier gas flow rate on lead detection.

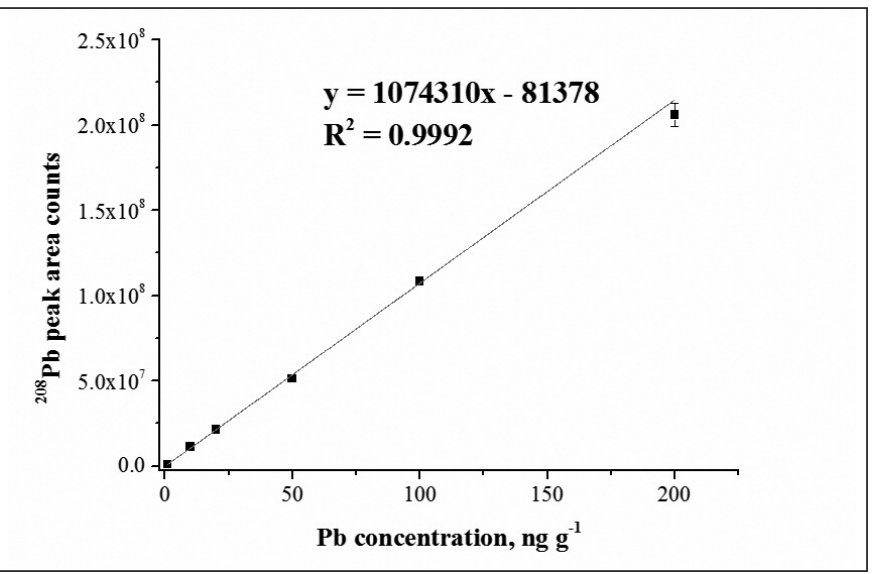

Fig. 5. PVG calibration curve generated from standard solutions containing $1.75 \% \mathrm{NaCl}, 10 \%$ formic acid, and $15 \mu \mathrm{g} \mathrm{g} \mathrm{Ni}^{-1}$. 
TABLE III

Determination of $\mathbf{P b}$ in Seawater

\begin{tabular}{lccc}
\hline Sample and Method & $\begin{array}{c}\text { Determined } \\
\mathrm{ng} \mathrm{g}^{-1} \\
(\mathrm{SD}, \mathrm{n}=3)\end{array}$ & $\begin{array}{c}\text { Spiked Value } \\
\mathrm{ng} \mathrm{g}^{-1} \\
(\mathrm{SD}, \mathrm{n}=3)\end{array}$ & $\begin{array}{c}\text { Spike Recoveries } \\
(\%)\end{array}$ \\
\hline Sanya (Std. Add.) & $0.26 \pm 0.04$ & 0.30 & $108.9 \pm 8.0$ \\
Haikou (Std. Add.) & $0.14 \pm 0.01$ & 0.30 & $106.2 \pm 7.7$ \\
Shanghai (Std. Add.) & $1.29 \pm 0.02$ & 1.00 & $95.2 \pm 1.6$ \\
\hline
\end{tabular}

TABLE IV

PVC-ICP-MS Determination of $\mathrm{Pb}$ in a Certified Seawater Sample

\begin{tabular}{lcc}
\hline Sample & $\begin{array}{c}\text { Determined } \\
\mathrm{ng} \mathrm{g}^{-1}(\mathrm{SD}, \mathrm{n}=3)\end{array}$ & $\begin{array}{c}\text { Certified } \\
\mathrm{ng} \mathrm{g}^{-1}(\mathrm{k}=2)\end{array}$ \\
\hline QC3163 Seawater & $691 \pm 17.8$ & $693 \pm 6.4$ \\
\hline
\end{tabular}

To further demonstrate the analytical accuracy of this method, the spiked recovery test was applied. The recoveries of spiking $0.3 \mathrm{ng} \mathrm{g}^{-1}$ and $1.00 \mathrm{ng} \mathrm{g}^{-1}$ of $\mathrm{Pb}$ into the seawater samples were in the range of 95.2-108.9\%. The developed method was also applied for the analysis of a certified seawater sample. The analytical result is shown in Table IV and is in agreement with the certified values, confirming the accuracy of the proposed methodology.

\section{CONCLUSION}

A novel and sensitive approach is developed for the direct determination of $\mathrm{Pb}$ in seawaters using nickelassisted PVG for sample introduction with ICP-MS detection. The severe matrix effect from seawater was efficiently eliminated by using $10 \%$ (v/v) formic acid and $15 \mu \mathrm{g} \mathrm{g}^{-1}$ $\mathrm{Ni}^{2+}$ as the photochemical reductant medium, making direct determination of $\mathrm{Pb}$ in seawater feasible. The method provides a detection limit of $0.003 \mathrm{ng} \mathrm{g}^{-1}$ for $\mathrm{Pb}$ using external calibration, suitable for ultratrace determinations of $\mathrm{Pb}$ in seawaters. The proposed method has promising application for the determination of trace $\mathrm{Pb}$ in seawater samples.

\section{ACKNOWLEDGMENT}

Sichuan Youth Science and Technology Foundation (No. 2017JQ0043), China Postdoctoral Science Foundation (No. 2016M590870), State Key Laboratory of Geohazard Prevention and Geoenviroment Protection Independent Research Project (SKLGP2016Z006), the Education Department of Sichuan Province (Grant No. 17ZA0040) and the Cultivating Program of Middle-aged Backbone Teachers Program of Chengdu University of Technology (Grant No. KYGG201409) are acknowledged for their financial support. The authors declare no competing financial interest.

Received January 11, 2017.

\section{REFERENCES}

1. C. Christophoridis, D. Dedepsidis, and K. Fytianos, J. Hazard. Mater. 168, 1082 (2009).

2. Y. Dong, R.K. Rosenbaum, and M.Z. Hauschild, Environ. Sci. \& Technol. 50, 269 (2016).

3. K. Chen, L. Huang, B. Yan, H. Li, H. Sun, and J. Bi, Environ. Sci. \& Technol. 48, 12930 (2014).
4. D. Absalon and B. Slesak, Science of the Total Environment 408, 4420 (2010).

5. R.L. Boeckx, Anal. Chem. 58, 274A (1986).

6. Y. Li, R.J. Yang, A.B. Zhang, and S.R. Wang, Mar. Pollut. Bull. 85, 700 (2014).

7. M. Komarek, V. Ettler, V. Chrastny, and $M$. Mihaljevic, Environ. Int. 34, 562 (2008).

8. M.F. Soto-Jimenez, F. Paez-Osuna, G. Scelfo, S. Hibdon, R. Franks, J. Aggarawl, and A.R. Flegal, Marine Environmental Res. 66, 451 (2008).

9. J.F. Wu and E.A. Boyle, Geochim. Cosmochim. Acta 61, 3279 (1997).

10. S. Hill, Inductively Coupled Plasma Spectrometry and its Application, Blackwell Publishing, Oxford, UK, 98 (2007).

11. W. Xu, S.J. Ni, Y. Gao, and Z.M. Shi, Spectrosc. Lett. 48, 542 (2015).

12. J.M. Lee, E.A. Boyle, Y. EchegoyenSanz, J.N. Fitzsimmons, R.F. Zhang, and R.A. Kayser, Anal. Chim. Acta 686, 93 (2011).

13. D.V. Biller and K.W. Bruland, Mar. Chem. 130, 12 (2012).

14. C.K. Su, T.W. Lee, and Y.C. Sun, J. Anal. At. Spectrom. 27, 1585 (2012).

15. J.E. O'Sullivan, R.J. Watson, and E.C.V. Butler, Talanta 115, 999 (2013).

16. N. Garcia-Otero, C. Teijeiro-Valino, J. Otero-Romani, E. Pena-Vazquez, A. Moreda-Pineiro, and P. BermejoBarrera, Anal. Bioanal. Chem. 395, 1107 (2009).

17. T. Minami, W. Konagaya, L.J. Zheng, S. Takano, M. Sasaki, R. Murata, Y. Nakaguchi, and Y. Sohrin, Anal. Chim. Acta 854, 183 (2015).

18. D. Weiss, E.A. Boyle, V. Chavagnac, M. Herwegh, and J.F. Wu, Spectrochim. Acta Pt. B, At. Spectrosc. 55, 363 (2000).

19. Y. Gao, R. Liu, and L. Yang, Chin. Sci. Bull. 58, 1980 (2013).

20. K. Huang, H. Xia, M. Li, Y. Gao, C. Zheng, and X. Hou, Analytical Methods 4, 4058 (2012). 


\section{A Spectroscopy $_{\text {pec }}^{\text {tom }}$ \\ 1 Vol. 38(3),May/June 2017}

21. V. Yilmaz, Z. Arslan, and L. Rose, Anal. Chim. Acta 761, 18 (2013).

22. X. Guo, R.E. Sturgeon, Z. Mester, and G.J. Gardner, Anal. Chem. 76, 2401 (2004).

23. Y. Yin, J. Liu, and G. Jiang, TracTrends in Anal. Chem. 30, 1672 (2011).

24. C. Zheng, Q. Ma, L. Wu, X. Hou, and R.E. Sturgeon, Microchem. Journal 95, 32 (2010).

25. Y. Gao, M. Xu, R.E. Sturgeon, Z. Mester, Z. Shi, R. Galea, P. Saull, and L. Yang, Anal. Chem. 87, 4495 (2015).

26. H.L. Duan, N.N. Zhang, Z.B. Gong, W.F. Li, and W. Hang, Spectrochim. Acta Part B, At. Spectrosc.120, 63 (2016).

27. X.M. Guo, R.E. Sturgeon, Z. Mester, and G.J. Gardner, Anal. Chem. 75, 2092 (2003).

28. Y. Gao, R.E. Sturgeon, Z. Mester, X. Hon, C. Zheng, and L. Yang, Anal. Chem. 87, 7996 (2015).

29. Y. Gao, R.E. Sturgeon, Z. Mester, X. Hou, and L. Yang, Anal. Chim. Acta 901, 34 (2015).

30. Y. Zeng, C. Zheng, X. Hou, and S. Wang, Microchem. Journal 117, 83 (2014).

31. H.L. Duan, Z.B. Gong, and S.F. Yang, Journal of Anal. At. Spectrom. 30, 410 (2015).

32. R.E. Sturgeon, Anal. Chem. 87, 3072 (2015).

33. Y.L. Wang, L.L. Lin, J.X. Liu, X.F. Mao, J.H. Wang, and D.Y. Qin, Analyst 141, 1530 (2016).

34. P.K. Petrov, G. Wibetoe, and D.L. Tsalev, Spectrochim. Acta Part B, At. Spectrosc. 61, 50 (2006). 